\title{
COOPERAÇÃO INTERNACIONAL E EQUIDADE: SERÁ POSSÍVEL?*
}

\author{
Adriana Rivoire Menelli de Oliveira \\ da Faculdade de Tecnologia SENAI Porto Alegre; \\ Marília Costa Morosini \\ da Pontifícia Universidade Católica do Rio Grande do Sul.
}

\begin{abstract}
REsUMO: O estudo aborda questões sobre equidade na cooperação internacional entre instituições universitárias e as possibilidades de trocas de experiências entre alunos de outros países. A maioria das políticas públicas de mobilidade acadêmica está voltada à relação Norte-Norte e/ou Sul/Norte. Mais recentemente, registra-se uma leve tendência a intercâmbios Sul/Sul - que visam garantir a inclusão de estudantes de países com necessidades de desenvolvimento social e econômico, como Angola, Moçambique, Haiti e Timor Leste, entre outros. O texto cita uma experiência realizada em instituição de ensino superior brasileira que oportunizou a convivência de estudantes estrangeiros, oriundos da África, Oceania e América Central, em seus espaços acadêmicos, durante o período de duração de sua formação na graduação. Tal experiência trouxe à luz o debate teórico sobre novas possibilidades de intercâmbio, inclusão de estudantes e a equidade na educação superior, fundamentadas na lógica da solidariedade.
\end{abstract}

PALAVRAS-CHAVE: Internacionalização. Educação superior. Equidade. Cooperação internacional horizontal.

INTRODUÇÃO

O intercâmbio internacional de estudantes tem apresentado uma alta taxa de expansão, seguindo o contexto mundial da globalizaçao. Esse aumento de intercâmbio pode ser explicado a partir de diferentes paradigmas.

\footnotetext{
* Artigo recebido em 10/09/2012 e aprovado em 05/12/2012.
} 
Em um dos extremos, identifica-se o paradigma mercantilista (sintentizado na rodada de Dohra, ainda em realização), pelo qual a educação é analisada como serviço e gerida por organismos multilaterais para a garantia de qualidade fundamentadora da regulação, com fins de possibilitar o desenvolvimento da educação transnacional. ${ }^{1}$

Destacam-se, por essa perspectiva, relações econômicas de dominação, tais como a captação de fundos - advinda do pagamento de taxas e mensalidades por estudante e a sua manutenção física propriamente dita -e a "venda do saber", assim como o desenvolvimento de laços que alimentam o consumo acadêmico nos países consumidores. A realização de estudos em um determinado país acarreta, pelo resto da vida, uma ligação à bibliografia produzida naquele país, aos seus professores e instituições e o retorno ao mesmo para a continuidade dos estudos.

Um outro paradigma que busca explicar a importância dos intercâmbios internacionais é a concepção da Instituição de Ensino Superior (IES) como ente universitário, marcado pela circulação livre do conhecimento para a consolidação da produção científica de relevância social e sintetizado na utopia da era do ouro do conhecimento.

Entre esses paradigmas, inúmeras complexificações se antepõem. Via de regra, os indicadores internacionais para intercâmbio são produzidos por e para uma realidade sócio-histórica desenvolvida (MADERA, 2006; REEB-GRUBER, 2009; CHING \& CHING, 2012; KNIGHT, 2011; SARRICO, 2012). Mas em uma realidade com grandes contradições internas, para que a internacionalização exerça um papel de auxilio à construção de uma identidade $e$ do desenvolvimento socioeconômico, podemos utilizar alguns indicadores mais tradicionais e standards, aos quais devem ser incluídos outros, em uma perspectiva de solidariedade, como aponta Didriksson (1966), na cooperação internacional horizontal. Assim, há que se considerar:

- fortalecer una política de diálogo e intercambio de información sobre temas y experiencias de interés común para crear un ambiente de colaboración y responsabilidades compartidas.

- incrementar el trabajo en redes para propiciar proyectos conjuntos que enlacen a las comunidades académicas y directivas entre sí y con otras regiones del mundo;

- aumentar el trabajo y de los aportes de los organismos multilaterales de la región en la promoción de nuevas formas de cooperación e integración;

- intensificar la solidaridad internacional y el mutuo reconocimiento; 
- facilitar la movilidad académica y estudiantil, acelerando el reconocimiento de créditos, grados, estudios, diplomas, desde la óptica de la confianza mutua y las equivalencias de calidad. Promover asimismo, programas específicos que tiendan a garantizar el libre tránsito de académicos y estudiantes de forma interinstitucional y multiplicar los programas de intercambio a todos los niveles;

- desarrollar mayores lazos de colaboración ya sea a nivel interinstitucional, entre asociaciones profesionales, autoridades, empresas y organismos de todo tipo para mejorar las condiciones de enseñanza e investigación;

- promover la capacitación de expertos y técnicos en la gestión y la administración de recursos multilaterales desde la perspectiva de una cooperación horizontal compartida;

- propiciar reuniones que tiendan a poner en marcha programas de colaboración y suscribir convenios que permitan compartir recursos de todo tipo para articular acciones académicas comunes;

- facilitar la participación de las instituciones de educación superior de la región en los foros internacionales, multilaterales, gubernamentales y no-gubernarnentales como instancias del bien común para garantizar la vigencia del servicio educativo como responsabilidad de toda la sociedad. (MOROSINI, 2012)

Nesse contexto de incertezas, no decorrer dos últimos anos, o Brasil tem efetuado acordos de cooperação internacional com diversos países, visando à ampliação da mobilidade acadêmica dos estudantes da graduação e da pós-graduação. A maioria desses acordos é voltada ao Norte - países desenvolvidos - mas alguns também, às relações Sul-Sul.

Para cumprir os Objetivos de Desenvolvimento do Milênio (Unesco, 2010) - focado na garantia dos direitos dos cidadãos, na redução da pobreza e das desigualdades -, o Brasil tem se apoiado em um conjunto de políticas sociais estruturadas e de alcance nacional. É declarado que"o grande desafio que se coloca à humanidade atualmente é o de anular a marginalização dos países e dos indivíduos que estão fora dos benefícios da globalização" (DIAS SOBRINHO, 1994, p. 132).

Considerando experiências educativas diferenciadas e de cunho social, o presente texto discorre sobre o tema da cooperação acadêmica internacional, a partir dessa experiência de uma instituição de educação superior, que recebeu estudantes estrangeiros de países da África, da Oceania e da América Central, entre os anos de 2005 e 2007. 
A pesquisa, realizada como estudo de caso, ressalta a equidade como elemento fundamental para o avanço da qualidade de ensino na educação superior, assim como a importância do resgate do papel da universidade como promotora de conhecimento e desencadeadora de mudanças para a constituição de uma sociedade ética, equitativa, justa e solidária. A investigação apresenta, também, alguns desafios enfrentados para a consecução da cooperação acadêmica horizontal.

\section{EDUCAÇÃO SUPERIOR E A COOPERAÇÃO INTERNACIONAL}

O Brasil vem oferecendo Programas de Cooperação Técnica Internacional em diversas ações para o desenvolvimento, sobretudo, em quatro áreas: capacitação, saúde, agricultura e assistência humanitária. Entre 2003 e 2009, o governo brasileiro promoveu a negociação, aprovação e implementação de mais de 400 acordos, ajustes, protocolos e memorandos de entendimento com governos de países em desenvolvimento da América Latina, Caribe, África, Ásia e Oceania. Esse mesmo período testemunhou um crescimento superior a $150 \%$ no número de países beneficiários da cooperação brasileira (de 21 para 56 países), com uma carteira de projetos e atividades da ordem de US\$ 90 milhões. Somente na África, a cooperação brasileira atende atualmente a 22 países, com um orçamento total de aproximadamente US\$ 45 milhões. A pauta de cooperação brasileira foi fortemente potencializada a partir da intensa agenda de missões presidenciais brasileiras ao continente africano nos últimos anos. Para a América Latina têm sido destinados US\$ 40 milhões, e outros US\$ 5 milhões para oTimor-Leste. O Brasil tem se destacado nos Objetivos de Desenvolvimento do Milênio (ODMs) com um desempenho muito bom nos indicadores do ODM 8: estabelecer uma parceria mundial para o desenvolvimento (BRASIL, 2012).

De acordo com os dados históricos, os anos de 1970 foram marcados pelas lutas dos espaços democráticos de resistência no Brasil, tendo em vista o regime de ditadura vivido na época. Organizações da sociedade civil surgem com o intuito de garantir os espaços de participação e de dinamismo social para o país. O processo de busca da cooperação internacional possibilitou a construção de fortes laços entre as instituições acadêmicas brasileiras, americanas e europeias.

Já na década de 1980, com o advento da Constituinte, o papel da cooperação internacional foi o de apoiar a construção de uma democracia mais participativa, ampliando a atuação das Organizações Não Governamentais (ONGs) na formulação de políticas públicas para o país. Nesse momento, surgem movimentos sociais constituídos em defesa das minorias raciais, 
indígenas, de gênero, do Movimento Sem Terra, entre muitos outros que ganham voz na sociedade.

Nos anos 1990, há uma mudança na organização da cooperação, que se concentra no aumento das fontes internacionais de apoio e recursos para a sociedade civil brasileira. Com maior abertura democrática, o Brasil passa a ser de interesse para a cooperação internacional quanto ao recebimento de recursos.

Na virada para o século XXI, com o incremento da democracia e a melhoria da qualidade de vida no Brasil, assim como com o fortalecimento dos movimentos sociais, o país deixa de ser prioridade para o cenário internacional e passa a assumir o papel de financiador de recursos para países com maior necessidade de investimento, em especial os da África. Antes, nas três últimas décadas, recebia financiamento externo, agora assume papel de doador de recursos para países pobres.

Atualmente, o Ministério da Educação mantém relacionamento com diversos organismos internacionais - como a Organização das Nações Unidas para a Educação, a Ciência e a Cultura (Unesco), a Organização dos Estados Americanos (OEA), e a Organização dos Estados Ibero-Americanos para a Educação, a Ciência e a Cultura (OEI) - sobretudo, pela participação em programas e projetos em áreas prioritárias ao desenvolvimento e melhoria dos sistemas educacionais dos países.

A atuação brasileira projeta-se em fóruns internacionais destinados a promover a integração dos países na área educacional e técnica, como a Reunião de Ministros da Educação dos Países Membros do Mercosul, a Conferência de Ministros da Educação da Comunidade dos Países de Língua Portuguesa, a Reunião de Ministros da Educação do Conselho Interamericano de Desenvolvimento Integral da OEA e a Conferência Ibero-Americana de Educação.

Com relação à agência de fomento do Ministério da Ciência e Tecnologia (MCT/CNPq), essa oferece várias modalidades de bolsas aos alunos do ensino médio, graduação, pós-graduação, recém-doutores e pesquisadores já experientes. As bolsas são divididas em duas categorias principais: bolsas individuais no país e no exterior, e bolsas por quota, voltadas basicamente para os países desenvolvidos, marcando aquilo que Didriksson (1966) denomina de cooperação tradicional.

Um dos exemplos é o programa Ciência Sem Fronteiras, ${ }^{2}$ lançado em 26 de julho de 2011, cujo propósito é promover a consolidação, expansão e internacionalização da ciência e tecnologia, da inovação e da competitividade brasileira, por meio do intercâmbio e da mobilidade internacional em universidades qualificadas, e em áreas (como engenharias e saúde) consideradas, pelo governo brasileiro, prioritárias ao desenvolvimento. 
Outra possibilidade de mobilidade acadêmica, promovida pelo Ministério da Educação, é o Programa de Estudantes-Convênio de Graduação (PEC-G), que oferece oportunidades de formação superior a cidadãos de países em desenvolvimento, com os quais o Brasil mantém acordos educacionais e culturais. ${ }^{3}$

O Programa de Estudantes-Convênio de Pós-Graduação (PEC-PG) objetiva a formação de recursos humanos, com vista a possibilitar cidadãos estrangeiros (de países em desenvolvimento) realizarem estudos de pós-graduação em Instituição de Ensino Superior brasileira. O PEC-PG ${ }^{4}$ constitui atividade de cooperação educacional, exercida exclusivamente com os países com os quais o Brasil mantém Acordo de Cooperação Cultural e Educacional. Esse programa é apoiado, em conjunto, pelo CNPq/Capes e pela Divisão de Temas Educacionais (DCE) do Ministério das Relações Exteriores (MRE).

Conforme o PEC-G, o aluno estrangeiro selecionado cursa gratuitamente a graduação, mas em contrapartida deve atender a alguns critérios; entre eles, provar que é capaz de custear suas despesas no Brasil, ter certificado de conclusão do ensino médio ou curso equivalente, e proficiência em língua portuguesa no caso dos alunos de nações fora da Comunidade de Países de Língua Portuguesa (CPLP). Os acordos determinam a adoção pelo aluno do compromisso de regressar ao seu país e contribuir com a área na qual se graduou (MEC/PEC-G, 2010).

Os dados estatísticos registram que, desde que se iniciou no ano 2000, o Programa tem recebido um número significativo de estudantes, conforme demonstra a Tabela 1.

Tabela 1 - Estudantes selecionados - Convênio de Graduação - PEC-G.

\begin{tabular}{|c|c|c|c|}
\hline Ano & África & América & Total PEC-G \\
\hline 2000 & 190 & 135 & 325 \\
\hline 2001 & 216 & 172 & 388 \\
\hline 2002 & 451 & 140 & 591 \\
\hline 2003 & 442 & 82 & 524 \\
\hline 2004 & 348 & 52 & 400 \\
\hline 2005 & 650 & 130 & 780 \\
\hline 2006 & 594 & 122 & 717 \\
\hline 2007 & 323 & 121 & 444 \\
\hline 2008 & 605 & 116 & 721 \\
\hline 2009 & 660 & 110 & 767 \\
\hline 2010 & 289 & 115 & 404 \\
\hline Total & 4768 & 1295 & 6061 \\
\hline
\end{tabular}

Fonte: MEC/SESu - PEC-G 2010. 
Conforme os dados estatísticos do PEC-G, sobre o número de estudantes selecionados entre 2000 e 2010, até o presente momento, dos 6.061 participantes do Programa, 4.768 são de países da África e 1.295 da América. O ano de 2005 foi o que recebeu maior adesão, seguido de 2009, com 767 estudantes. Em 2010, somente 404 participaram do Programa, sendo 289 estudantes da África e 115 da América.

Atualmente, o Programa conta com a adesão de 90 IES brasileiras, distribuídas em todas as regiões do país. Conta com a representação de 45 países, sendo Cabo Verde, Guiné-Bissau, Angola e República Democrática do Congo os que têm o maior número de estudantes nas IES brasileiras (MEC/PEC-G, 2010). Em 2010, foram ofertadas 2.568 vagas para estudantes estrangeiros pelo PEC-G, sendo as regiões Sul e Sudeste as mais procuradas pelos interessados.

Considerando as políticas internacionais de aproximação do Brasil com países do eixo Sul-Sul - reforçadas pela ONU de que não somente os eixos Norte-Norte e Norte-Sul fossem considerados -, em 22 de março de 2009, o governo brasileiro e a Organização Internacional do Trabalho (OIT) assinaram um novo acordo de parceria complementar para a cooperação Sul-Sul. O Brasil reiterou seu compromisso para que a cooperação Sul-Sul contribua para a melhoria da capacidade dos estados-membros da OIT em cumprir com as normas internacionais do trabalho, em concordância com o que é previsto na Declaração da OIT para a justiça social e uma globalização equitativa. É esperado que o acordo "impulsione o intercâmbio de experiências e boas práticas para combater a pobreza nos países em desenvolvimento, incluindo os sistemas de transferência condicional de renda, os programas para combater o trabalho infantil, o desenvolvimento da proteção social através de esquemas de seguridade social para a promoção do emprego juvenil e o trabalho decente para mulheres e homens" (OIT. UNIC, Rio de Janeiro, 2009).

Um dos programas de destaque chama-se Mobilidade Acadêmica Regional em Cursos Acreditados (Marca), desenvolvido e implementado pelo Setor Educacional do Mercosul, ${ }^{5}$ atendendo a duas prioridades do planejamento estratégico do setor: a melhoria da qualidade acadêmica, por meio de sistemas de avaliação e acreditação, e a mobilidade de estudantes, docentes e pesquisadores entre instituições e países.

A cooperação técnica e de mobilidade acadêmica no Brasil ainda é muito recente, tendo em vista a trajetória e o processo de consolidação dos seus direitos democráticos alcançados pela sociedade civil nas três últimas décadas, mas avança, paulatinamente, para se estabilizar entre as parcerias já firmadas e ampliar os laços com outros países em relação à cooperação internacional. 
Além disso, Haddad (Unesco, 2010) declara que"um sistema é equitativo quando os resultados da educação e da formação são independentes do meio socioeconômico e de outros fatores geradores de desvantagens educativas, e quando o tratamento reflete as necessidades específicas dos indivíduos em matéria de aprendizagem".

\section{MobILIDADE ACADÊMICA E OS ESTUDANTES ESTRANGEIROS}

De forma a enriquecer o debate sobre intercâmbios internacionais e equidade, o estudo traz o caso de uma instituição de educação superior que procurou inovar sua proposta acadêmica, promovendo acordos de cooperação internacional com base nas relações de equidade.

O Projeto Político Pedagógico institucional da IES (IPA, 2004) contempla ações nas áreas do ensino, pesquisa e extensão que desafiam as práticas de inclusão em todos os âmbitos da vida acadêmica, desenvolvendo planos que ampliam a visão de mundo no que tange às oportunidades e ao acesso de todos que fazem parte da sociedade. Isso é, sem nenhum veto à inclusão. Para tanto, define políticas de relação com a comunidade interna e externa, de acordo com as necessidades de cada um, como, por exemplo, quando instituiu, no Concurso Vestibular de 2004, um número de cotas para o ingresso de candidatos oriundos das comunidades indígenas, do movimento dos trabalhadores sem-terra, do centro ecumênico de cultura negra e do programa que desenvolve a capacitação das educadoras populares.

Nesse ano, quando da transformação da IES em Centro Universitário, estabeleceu-se uma política para intercâmbios acadêmicos internacionais por meio de convênios com universidades e instituições religiosas de outros países: dos EUA, da Alemanha e da Austrália.

Com início em 2005, o Programa de Cooperação Internacional recebeu 54 estudantes de graduação. Jovens do Haiti, Angola, Timor Leste ${ }^{6} \mathrm{e}$ Moçambique foram recebidos com bolsa de estudo, hospedagem, alimentação e apoio pedagógico (IPA, 2008).

Além do conhecimento para a formação profissional dos acadêmicos, o objetivo foi oportunizar formação a estudantes oriundos de regiões em situação de recuperação pós-guerra e vulnerabilidade social, como Moçambique, Angola, Timor Leste e Haiti (Quadro 1). O entendimento foi de que esses jovens estrangeiros poderiam auxiliar no desenvolvimento e no crescimento de seus países de origem, tendo em vista as dificuldades de ordem social, política ou econômica que têm assolado a realidade desses países em situação de risco. 
Quadro 1 - Estudantes Convênio, Paises em situação de pós-guerra e vulnerabilidade social, IPA, 2005.

\begin{tabular}{|c|c|c|c|}
\hline HAITI & ANGOLA & TIMOR LESTE & MOÇAMBIQUE \\
\hline \multirow{2}{*}{ Ed. Física (2) } & \multirow{2}{*}{$\begin{array}{l}\text { Publicidade e } \\
\text { Propaganda (3) }\end{array}$} & \multirow{3}{*}{$\begin{array}{l}\text { Administração } \\
\text { Hospitalar }\end{array}$} & Direito (2) \\
\hline & & & Biomedicina (3) \\
\hline \multirow{2}{*}{ Fisioterapia (2) } & \multirow{2}{*}{ Enfermagem (5) } & & Neg. Intern. \\
\hline & & \multirow{2}{*}{ Farmácia } & Administração (2) \\
\hline Nutrição (2) & \multirow{2}{*}{\begin{tabular}{|c|} 
Negócios \\
Internacionais (2)
\end{tabular}} & & Nutrição \\
\hline \multirow{3}{*}{$\begin{array}{c}\text { Engenharia da } \\
\text { Computação (3) }\end{array}$} & & \multirow{2}{*}{ Enfermagem } & Biomedicina \\
\hline & Administração & & Arquitetura \\
\hline & \multirow{2}{*}{$\begin{array}{c}\text { Engenharia da } \\
\text { Computação (3) }\end{array}$} & \multirow[b]{2}{*}{ Fisioterapia } & Engenharia Civil \\
\hline Contabilidade & & & $\begin{array}{l}\text { Publicidade } \\
\text { e Propaganda }\end{array}$ \\
\hline Administração (2) & $\begin{array}{l}\text { Engenharia da } \\
\text { Produção }\end{array}$ & Direito & $\begin{array}{c}\text { Negócios } \\
\text { Internacionais }\end{array}$ \\
\hline
\end{tabular}

Fonte : OLIVEIRA, 2012.

Pelo fato de os estudantes estrangeiros habitarem as dependências da IES, em espaço especialmente preparado para seu acolhimento, ampliaram-se suas possibilidades de convívio entre os outros acadêmicos brasileiros, pois, além de se distribuírem entre os cursos de graduação, eles compartiIhavam espaços acadêmicos das salas de aula, da Biblioteca, do Refeitório, do Ginásio de Esportes, entre outros.

Um timorense ${ }^{7}$ afirma:

Então os pontos positivos são muitas coisas: a relação, o convívio, o sistema brasileiro de educação e a tecnologia. O Brasil é um país que tem uma educação muito avançada em termos de tecnologia, a gente tem mais facilidade de fazer pesquisa.

A esse respeito, o relato de um estudante brasileiro demonstra o quanto a convivência com os estrangeiros foi significativa:

Eu mesmo tive colegas, moçambicanos, angolanos e timorenses; é interessante perceber como a dinâmica modifica; quando estamos no exterior pressupomos a existência de contatos conflitivos e culturais e já vamos pré-dispostos a mudar nossas atitudes. No entanto, frequentemente, quando voltamos à terra natal, tudo volta ao normal (ao menos comigo sempre foi assim). Agora quando esses contatos se estabelecem justamente quando estamos na nossa zona de conforto, isso nos obriga a revisitar não apenas o nosso papel, mas também o papel da sociedade local em que estamos inseridos. (KEMPER, 2009) 
Propostas criativas e inovadoras são sempre capazes de desencadear releituras sobre determinados conceitos ou concepções. No caso do intercâmbio acadêmico proposto, as relações internacionais entre estudantes ocorreram para além da relação mercantilista da simples transmissão do conhecimento técnico e científico, do desenvolvimento de pesquisas, das trocas e dos interesses econômicos para uma relação de cooperação solidária entre povos e nações. A IES em questão estabeleceu uma atitude fraterna às diversas nações e reafirmou, perante a sociedade e a comunidade estudantil, a importância das relações de justiça, de solidariedade e de promoção humana.

Definidos os critérios para o ingresso de estudantes estrangeiros dentre eles, a certificação colegial e a aprovação da seleção pelo país de origem do candidato - convênios foram firmados com instituições estrangeiras parceiras. Outros critérios básicos diziam respeito aos aspectos de linguagem (como saber falar português) e às questões de interesse do país, como o compromisso de retorno à pátria ao término do curso, a fim de compartilhar o conhecimento adquirido na universidade.

Eu não tinha estudado em universidade em Timor, porque eu terminei ensino médio e vim direto, mas pelo que eu aprendi aqui, é muito legal porque aqui a gente aprende; a faculdade não fica só na teoria, a gente aprende na prática, fica mais valorizado pra nós e fica um aprendizado que a gente não esquece; no Timor a gente aprende mais na teoria, no livro, que na prática; é difícil. Pela situação de Timor mesmo.

Os grupos de estrangeiros iniciaram seus estudos no Brasil em épocas diferenciadas, sendo os de Moçambique, 17 estudantes, o primeiro grupo a chegar em março de 2005; os de Angola e do Timor Leste, em agosto de 2005, com 17 e 8 estudantes, respectivamente; e o do Haiti em 2007, com 12 estudantes.

Do total de alunos que chegaram em 2005 para a graduação, apenas 5 não conseguiram completar os cursos por motivos diversos, sendo um de Moçambique, um de Angola e 3 do Timor Leste. Os estudantes do Haiti terminaram seus cursos em dezembro de 2010.

Dos estudantes estrangeiros participantes do intercâmbio que retornaram a seus países e já trabalham nas suas áreas de formação, 13 são de Moçambique (dos demais, 2 ficaram no Brasil para fazer o mestrado, um desistiu e outro terminou o curso em 2011); 10 são de Angola (dos demais, 7 ficaram no Brasil para fazer pós-graduação); e 5 são do Timor Leste (dos demais, dois retornaram ao país sem completar o curso e outro decidiu morar no Brasil).

Entre as principais dificuldades é assinalada a convivência com culturas tão diferentes: 
Bom, a distância da família, para qualquer pessoa é difícil, porque não estamos dentro de um mesmo estado, mas em continentes diferentes. Quando eu tenho dinheiro, eu ligo ou eles ligam, falamos por telefone, por MSN ou e-mails. Mas eu fiz mais amigos do que eles todos (se refere aos outros estudantes timorenses). Porque eu convivi dentro da casa, [...] eu considero quem tá na minha frente, quem me acolhe, quem conversa comigo, a pessoa boa, eu também considero da minha família. Porque minha família tá longe, e mesmo perto, quem tá do meu lado também é meu amigo, meu irmão, minha irmã. Eu considero isso, essa questão da comunicação com minha família, de vez em quando eu fico com saudade. Mas eu não tô muito assim, toda hora com saudade.

A questão de adaptação à cultura brasileira foi apontada:

Nós temos uma cultura muito diferente, é chamada "fetosando". Por exemplo, um homem se casa com uma mulher e as famílias já têm uma ligação, então a descendência tem que ser casando, como o objetivo de não cortar os laços da família. Na capital quase não se tem mais essa cultura, por que tem muita influência das pessoas estrangeiras, mas no interior é complicado. Existe um dote das mulheres.

Com relação ao grupo de oito estudantes do Timor Leste, esse foi o que mais dificuldades enfrentou, tendo em vista a falta de recursos financeiros para se manterem no país e o rompimento do convênio entre as Igrejas Unidas da Austrália e do Timor Leste. Outra dificuldade enfrentada foi a distância e o afastamento das famílias, levando alguns estudantes a retornar ao país sem completar os estudos.

Advindos de uma região localizada no Sudeste asiático, oTimor Leste tem um passado de muitos conflitos. Após ter sido uma colônia portuguesa, foi invadido pelas tropas da Indonésia, país com que faz fronteira. A ocupação foi marcada pela resistência do povo timorense e pela opressão do governo. Em 1999, a população votou pela independência, através de um referendo realizado pela Organização das Nações Unidas (ONU).

Nas palavras de um timorense quando de sua volta à origem:

Na verdade a primeira coisa que quero é ver minha família, amigos. Mas em termo de profissional, o Timor precisa investir muito na área da saúde. Por exemplo, em hospitais. Eu gostaria de trabalhar em hospital um dia, se Deus quiser, porque em termos de hospitais há diferença, é muito grande. [...] Eu gostaria que tivesse no Timor.

Outro timorense afirma: 
Esse curso que eu faço, é importante para mim e para meu país - a questão da saúde pública...eu gostaria de trabalhar na saúde pública. Porque nossa saúde pública ainda é desestruturada e há falta de conhecimento. Então é isso, eu tenho muitas coisas para fazer nessa área da enfermagem [...]. Eu não quero trabalhar em hospital. Eu quero na comunidade, tipo construir um posto para um trabalho mais com a população.

Diante dessa realidade, os estudantes que concluíram formação acadêmica têm atualmente contribuído para a reconstrução de seus países de origem, de forma a resgatar a identidade de seu povo e buscar a constituição de uma nova sociedade. Nas palavras de um timorense, está ressaltado o compromisso com o ensino para melhorar o Timor:

Gostaria muito de me especializar logo, fazer mestrado aqui, para ingressar no acadêmico. Porque não adianta a gente ir para lá, trabalhar, ganhar muito dinheiro, mas a gente não contribuir com conhecimento, com aquilo que a gente aprendeu aqui. Não vale a pena. Então, eu gostaria, sim, de fazer mestrado, doutorado, voltar para sala de aula.

As expectativas ao retornar para o Timor Leste no que se refere ao mundo do trabalho são expressas como:

Muitas coisas. Mas como na minha profissão eu gostaria muito de aplicar o que eu aprendi aqui, na parte da assistência farmacêutica, atenção farmacêutica, uso racional de medicamentos. Essas coisas são muito importantes lá.

Com o término dos estudos dos estrangeiros advindos dos países africanos, Timor Leste e Haiti, a instituição decidiu não mais dar continuidade ao programa, tendo em vista seu alto custo. Considerou-se, também, a rede de estrutura e organização necessária para que as estudantes se estabelecessem com segurança e atingissem os objetivos propostos, como a formação acadêmica. Da mesma forma, na avaliação realizada, o grupo gestor ponderou que o formato do programa deveria ser revisto, considerando: a hospedagem oferecida pela instituição que financiava praticamente todos os custos dos estudantes; o acompanhamento pedagógico e comunitário que requeria equipes de atendimento personalizado e especializado; como também, as bolsas de estudo de $100 \%$ ofertadas pela IES.

\section{ConsiderAções}

Fernandez Lopes acredita que os países desenvolvidos deveriam ajudar a estabelecer os mecanismos necessários para impulsionar pessoas qualificadas a retornar a seus países de origem para que, com sua formação, 
contribuam com o desenvolvimento socioeconômico dos mesmos. Uma medida possível seria destinar uma porcentagem da ajuda internacional para a cooperação e o estabelecimento de centros de investigação nos países em desenvolvimento, onde o pessoal mais qualificado seguiria suas pesquisas com o apoio externo de colegas dos países desenvolvidos (FERNANDEZ LOPES, 2007, p. 174).

Para a Unesco (2009), "promover a equidade de acesso e a inclusão constitui elemento essencial das políticas, junto com a garantia de qualidade, especialmente no contexto de uma sociedade globalizada, e a diversificação da oferta de ensino superior..." (p. 7). Essa posição, portanto, vem ratificar as tendências sobre a necessidade e o desenvolvimento de ações fraternas de cooperação internacional entre países. Na fala de um entrevistado timorense fica clara essa necessidade:

O Brasil tá ajudando muito o Timor através da educação, [...] é muito importante, porque é um país novo e passa muitas dificuldades, conflitos, e eu gostaria que através da cooperação com o Brasil possa melhorar o sistema de educação do nosso país e o português possa se expandir no território do Timor [...] o Brasil tá lá no Timor, tá ajudando, contribuindo para melhorar o sistema de educação de lá.

Entretanto, não somos ingênuos para declarar que experiências significativas no âmbito da academia - como a anteriormente considerada, com estudantes de países em situação de desenvolvimento - enquadram-se perfeitamente no paradigma da equidade, da solidariedade, citado no inicio do texto. Há inúmeros desafios a serem vencidos, desde os burocráticos - os desentendimentos entre IES, a interrupção abrupta de programas, o corte de financiamento etc. - até os interesses econômicos subjacentes com a própria consideração da educação como serviço. Há muito que se avançar na direção de políticas públicas, voltadas ao favorecimento da mobilidade entre estudantes e que elevam a universidade à sua verdadeira missão social, de ser um bem público e de direito fundamental do ser humano.

Tal concepção exigirá mudanças paradigmáticas profundas com relação às realidades geoeconômicas diferenciadas, refletindo-se no ensino, na pesquisa, na gestão, nos projetos pedagógicos e na atuação de educadores e de dirigentes das universidades, que têm o compromisso com a constituição de uma sociedade mais justa, humana e solidária.

É possível existir a cooperação internacional e a equidade, mas, de forma especial, através de fortes politicas públicas, voltadas à cooperação horizontal internacional. 


\section{INTERNATIONAL COOPERATION AND EQUITY: IS IT POSSIBLE?}

ABSTRACT: The study addresses issues of equity in terms of international cooperation between universities and the possibilities for exchange experiences with students from other countries. Most policies for academic mobility are directed to the NorthNorth and/or South-North. More recently, a slight tendency towards South-South exchanges has been seen to guarantee that students from countries with social and economic development needs, such as Angola, Mozambique, Haiti and East Timor, among others, also be included. The text cites an experiment conducted in a Brazilian Institute of Higher Education, which provided study opportunities for students from Africa, Oceania and Central America, for the duration of their undergraduate education. This experience brought to light the theoretical debate about new possibilities for student exchange and inclusion and equity in higher education, based on the logic of solidarity.

Keywords: Internationalization. Higher Education. Equity. Horizontal International Cooperation.

\section{COOPERACIÓN INTERNACIONAL Y EQUIDAD: ¿SERÁ ESO POSIBLE?}

RESUMEN: El estudio aborda aspectos sobre equidad en la Cooperación Internacional entre instituciones universitarias y las posibilidades de intercambio de experiencias entre alumnos de otros países. La mayor parte de las políticas públicas de mobilidad académica están orientadas a la relación norte-norte e/ou sur/norte. Recientemente, se ha registrado una leve tendencia a intercambios sur/sur - que buscan garantizar la inclusión de estudiantes de países con necesidades de desarrollo social y económico, como Angola, Mozambique, Haiti y Timor Oriental, entre otros. El texto menciona una experiencia realizada en una institución de enseñanza superior brasileña, que dio oportunidad para la convivencia con estudiantes extranjeros provenientes de África, Oceanía y América Central, en sus espacios académicos, durante su período de formación universitaria. Tal experiencia trajo a luz el debate teórico sobre nuevas posibilidades de intercambio, inclusión de estudiantes y la equidad en la educación superior, fundamentados en una lógica de la solidaridad.

Palabras Claves: Internacionalización. Educación Superior. Equidad. Cooperación Internacional Horizontal.

\section{NOTAS}

1. A concepção de educação como serviço pode adquirir diferentes formas: uma primeira é a oferta transfronteiriça de educação que não implica em deslocamentos de alunos e professores; uma segunda que é classificada como consumo no estrangeiro através da mobilidade de alunos; uma terceira aponta para a presença comercial 
da educação em outro país como, por exemplo, uma sede local, campus-satélite, franquias etc.

2. O programa tem como meta atender 75.000 bolsas oferecidas pelo governo federal e 26.000 pela iniciativa privada, totalizando 101.000 bolsas a estudantes e pesquisadores, no país e no exterior; os investimentos irão superar a marca de R\$ 3.2 bilhões até 2015 .

3. Desenvolvido pelo Ministério das Relações Exteriores e da Educação, em parceria com universidades públicas - federais e estaduais - e particulares, o PEC-G seleciona estrangeiros, entre 18 e 25 anos, com ensino médio completo, para realizar estudos de graduação no país (MEC/PEC-G, 2010).

4. O programa concede bolsas de mestrado (até 24 meses - bolsa do CNPq) e doutorado (até 48 meses - bolsa da Capes) para estrangeiros que venham realizar pós-graduação no Brasil. Os valores das bolsas aos estrangeiros são equivalentes aos pagos a estudantes brasileiros. Além disso, há outros benefícios: isenção de taxas escolares, as quais são custeadas de acordo com as normas e critérios das agências, e passagem aérea de retorno aos bolsistas que defenderem dissertação/tese.

5. De acordo com a proposta, participam do programa cursos de graduação avaliados e aprovados pelo Sistema de Acreditação Regional de Cursos Universitários do Mercosul (ARCU-SUL), pertencentes a instituições dos quatro países membros (Argentina, Brasil, Paraguai e Uruguai) e dos países associados Bolívia e Chile. Estudantes desses cursos de graduação podem se candidatar a um intercâmbio de um semestre letivo em uma instituição de outro país. O programa é administrado por um convênio de vários órgãos dos países-membros. No Brasil, a Capes (Coordenação de Aperfeiçoamento de Pessoal de Nível Superior) e a Secretaria de Educação Superior do MEC são os responsáveis pela administração. Na Argentina, a atribuição está a cargo da Secretaria de Políticas Universitárias; no Uruguai, da Universidad de la República, e no Paraguai, da Direção-Geral de Educação Superior.

6. A esse respeito um intercambista do Timor Leste descreve a situação em seu país após a independência: “Em termos de econômico... depois da independência nós temos recursos naturais como ouro, como petróleo, que faz fronteira entre a Austrália. Mas no Timor nós temos fraquezas em termos de recursos humanos e recursos materiais também. O Timor faz, convênio com Austrália. Por enquanto os recursos, tanto materiais quanto humanos, é a Austrália que tenta desenvolver o petróleo. Em termos de cultura acho que muda muito depois da independência. Porque antes da independência nós tínhamos outra cultura... na maioria das vezes a cultura inglesa". Com relação às dificuldades afirma: "Tudo. Dificuldades financeiras, econômicas, educacionais. Vamos dizer, em termos de recursos tanto materiais quanto humanos. A gente do Timor já foi independente, mas ainda é dependente. Tu não tem recursos tal, tal, tal, então tu precisa de ajuda de outros países, então torna-se dependente também. Daí, temos muitas dificuldades."

7. Foram realizadas entrevistas com quatro timorenses na instituição em 2010, com o objetivo de conhecer a educação superior no seu país, as razões da vinda para estudar 
no Brasil e a avaliação do período de estudo no país, bem como os planos para o futuro, quando do retorno ao Timor. Um dos critérios de seleção foi a concordância em conceder o depoimento. As entrevistas foram realizadas no local de vivência dos estudantes já graduados a espera de retorno ao seu país.

\section{REFERÊNCIAS}

BRASIL. MINISTÉRIO DAS RELAÇÕES EXTERIORES, 2012. Disponível em: http://www. itamaraty.gov.br/. Acesso em: 28 jun. 2012.

CHING, G. S.; CHING, M. C. Managing Higher Education Institution Internationalization: contemporary efforts of a University at Taiwan. INTERNATIONAL JOURNAL OF RESEARCH STUDIES IN MANAGEMENT. Consortia Academia Publishing, 2012 April, v. 1, n. 1, p. 3-16.

DIAS SOBRINHO, J. (Org.). Avaliação institucional da Unicamp: processo, discussão e resultados. Campinas: Unicamp, 1994.

DIDRIKSSON, A. Reformulación de la cooperación internacional en la educación superior de América Latina y el Caribe. DC/C5/OA. UNESCO, 1966.

FERNÁNDEZ LÓPEZ, S.; FERNÁNDEZ ALFARO, S.; VAQUERO GARCÍA, A. Proyección internacional de los sistemas de educación superior de America Latina y el Caribe. Revista Ibero-Americana de Educación, n. 45, p. 159-175, sep./dec. 2007.

KNIGHT, J. Five myths about internationalization. INTERNATIONAL HIGHER EDUCATION. Boston: The Boston College Center for International Higher Education, v. 62, winter 2011, p. 14. Disponível em: http://www.bc.edu/research/cihe/ihe/issues/2011.html. Acesso em: 25 jan. 2012.

IPA. Projeto Político Pedagógico. Porto Alegre: IPA, 2004. (Mimeografado)

IPA. Relatório anual de responsabilidade social. Balanço social 2008. Porto Alegre: Rede Metodista de Educação do Sul, 2008. Disponível em: www.metodistasul.edu. br/redeipa/balanco_social/php. Acesso em: 12 jul. 2012.

KEMPER, C. V. T. In: BAPTISTA, D. Sociedade global. Cooperação Internacional para o Desenvolvimento (2009). Disponível em: http://internethos.ning.com/profile/DiegoHSBaptista. Acesso em: 26 nov. 2011.

MADERA, I. Un sistema de gestión de la internacionalización y la cooperación en la universidad APEC, como eje transversal de la dinámica institucional. V Congreso Internacional de Educación Superior, Universidad 2006. II Simposio de Internacionalización de la educación superior. 13-17 Febrero, Ministerio de Educación Superior (MES), Universidades de la República de Cuba/Unesco, 2006.

MOROSINI, M. C. (Ed.). Enciclopédia de pedagogia universitária: glossário. Brasília: INEP/ MEC, 2006. v. 2. 
MOROSINI, M. C.. Qualidade da educação superior e internacionalização: estado de conhecimento sobre indicadores. In: CUNHA, M. I. \& BROILO, C. (Org.). Qualidade na educação superior: grupos investigativos em diálogo. 1 ed. São Paulo: Marin \& Junqueira Eds., 2012.

OIT. C:IUsers \Adriana\Desktop \Brasil e OIT assinam acordo para ampliar cooperação Sul-Sul.mht, 2009. Acesso em: 28 nov. 2010.

OLIVEIRA, A. R. M. Qualidade da educação superior: um caso de equidade. II SEMINÁRIO INTERNACIONAL SOBRE ENSINO SUPERIOR NOS PAÍSES DA CPLP - Qualidade da educação superior: isomorfismo, diversidade e equidade. Anais. Universidade do Algarve, 2010.

REEB-GRUBER, S. Checklists program internationalization. Inholland University, 2009. Disponível em: http://www.nuffic.nl/international-organizations/docs/quality-assurance-and-internationalization/checklistis-program-internationalization-english-21-07-2009.pdf. Acesso em: 01 fev. 2012.

SARRICO, C. S. Indicadores de desempenho para apoiar os Processos de Avaliação e Acreditação de Cursos. Gab. de Estudos e Análise, A3 ES, 2010. Disponível em: http:// si.esgt.ipsantarem.pt/esgt_si/web_gessi_docs.download_file?p_name=F326257361/ Estudo_IndicadoresDesempenho_Cláudia Sarrico.pdf. Acesso em: 25 jan. 2012

UNESCO. Educação de qualidade, equidade e desenvolvimento sustentável: uma concepção holística inspirada nas quatro conferências mundiais sobre educação organizadas pela Unesco em 2008-2009 (2008). Disponível em: http://www.unesco.org/education/ es/sector. Acesso em: 27 nov. 2010.

UNESCO. IESALC. Entrevista Georges Haddad: Vamos hacia un nuevo paradigma de las universidades (2009). Disponível em: http://www.iesalc.unesco.org.ve/index. php?option=com_content\&view=article\&id=912:boletin-especial-iesalc-informa-no$-197 \&$ catid=101:destacados\&ltemid=450\%26\%239001\%3B=es. Acesso em: 29 nov. 2010.

ADRIANA RIVOIRE MENELLI DE OLIVEIRA: doutora em Educação pela PUCRS; pós-doutora pela PUCRS/Universidade do Texas; diretora da Faculdade de Tecnologia SENAI Porto Alegre.

E-mail: adriana.menelli@senairs.org.br

MARÍLIA COSTA MOROSINI: doutora em Educação/UFRGS; pós-doutora pela LLILAS/Utexas; professora PPGEdu/PUCRS; bolsista produtividade 1, CNPq.

E-mail: marilia.morosini@pucrs.br 